\title{
An Overview of the Mexican Blueberry Industry ${ }^{1}$
}

\author{
Feng Wu and Zhengfei Guan²
}

\section{Introduction}

Blueberries, a delicious fruit with a high nutritional value and few calories, are a heart-healthy source of antioxidants, vitamins, and fiber. Global consumer demand for blueberries is increasing at an annual growth rate of $12 \%$ (Rabobank 2019). Superb taste and health effects have driven the fast growth in consumer demand, boosting production from diverse regions. One of those regions is Mexico, where blueberry is a relatively new crop but production has seen exponential growth in recent years. As Mexico is becoming a major supplier in the US market, this publication aims to provide growers, policymakers, and the general public with an overview of the Mexican blueberry industry in terms of its production, prices, trade, and cultural practices. It will also shed light on factors that have contributed to the growth of the industry.

\section{Mexican Blueberry Production}

Mexican blueberry production has increased significantly in recent years. The acreage of blueberries grown in Mexico broke records almost every year over the period from 2009-2018. In 2018, the planted and harvested acreages reached 9,357 and 8,923 acres, respectively, almost 20 times higher than those in 2009 (Figure 1). As a result, Mexican blueberry production increased from 4 million pounds in 2009 to 89 million pounds in 2018. Blueberries are produced in 10 states of Mexico, with the major blueberry production area concentrated in Central Mexico, including Jalisco, Michoacán, and Sinaloa, which are also the major strawberry-producing states. The national average yield of blueberries was 9,948 pounds per acre (lb/acre) in 2018 . Sinaloa ranked highest, with an average yield of 16,059 lbs/acre, almost four times the yield in Florida, a major competitor of Mexican blueberries in the US market. The Mexican blueberry season covers the period from September through June, peaking between February and May, which overlaps the production window of Florida blueberries.

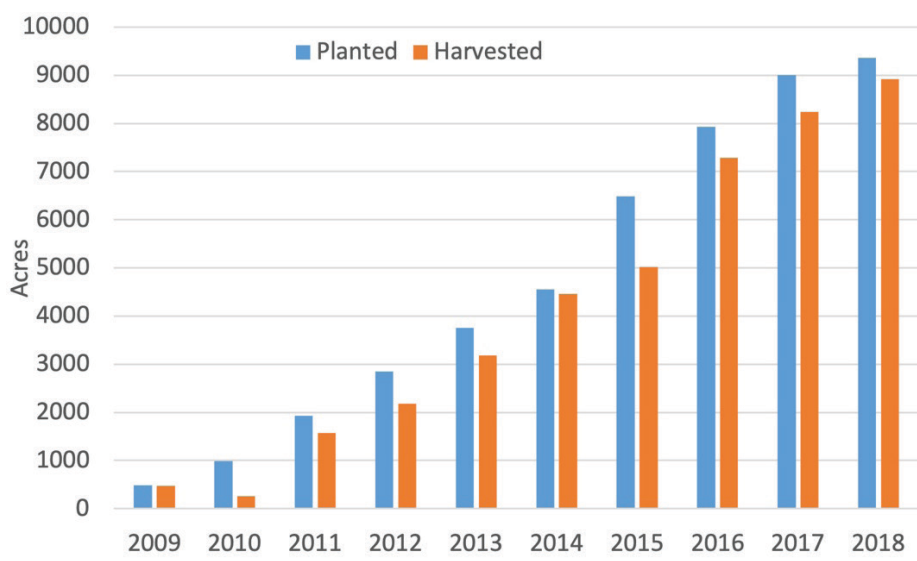

Figure 1. Mexican Blueberry Acreage, 2009-2018 Credits: SIAP, Mexico

\section{Mexican Blueberry Prices}

Prices received by Mexican growers have followed a prominent increasing trend since 2009. Figure 2 shows the movement of farm-gate prices of conventional blueberries in Mexico between 2009 and 2018. In 2009, the Mexican grower price was only 3 pesos per pound (equivalent to

1. This document is FE1 106, one of a series of the Food and Resource Economics Department, UF/IFAS Extension. Original publication date December 2021. Visit the EDIS website at https://edis.ifas.ufl.edu for the currently supported version of this publication.

2. Feng Wu, research assistant scientist, UF/IFAS Gulf Coast Research and Education Center; and Zhengfei Guan associate professor, UF/IFAS Food and Resource Economics Department, UF/IFAS Gulf Coast Research and Education Center.

The Institute of Food and Agricultural Sciences (IFAS) is an Equal Opportunity Institution authorized to provide research, educational information and other services

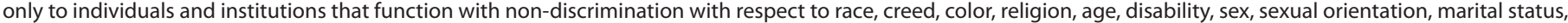

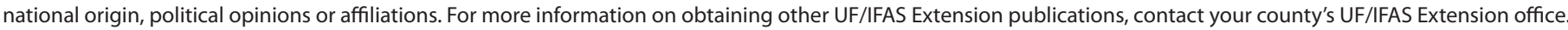
U.S. Department of Agriculture, UF/IFAS Extension Service, University of Florida, IFAS, Florida A \& M University Cooperative Extension Program, and Boards of County Commissioners Cooperating. Andra Johnson, dean for UF/IFAS Extension. 
US\$0.23), compared to a record high of 26 pesos per pound in 2017 (equivalent to US\$1.39). The price received by US blueberry growers in 2017 was US $\$ 2.05$. Increasing prices have encouraged Mexican growers to expand their scale of blueberry production or switch from other crops to blueberries. Although the price in Mexico in 2018 was slightly down, it remained at a high level, making it one of the most profitable crops in Mexico.

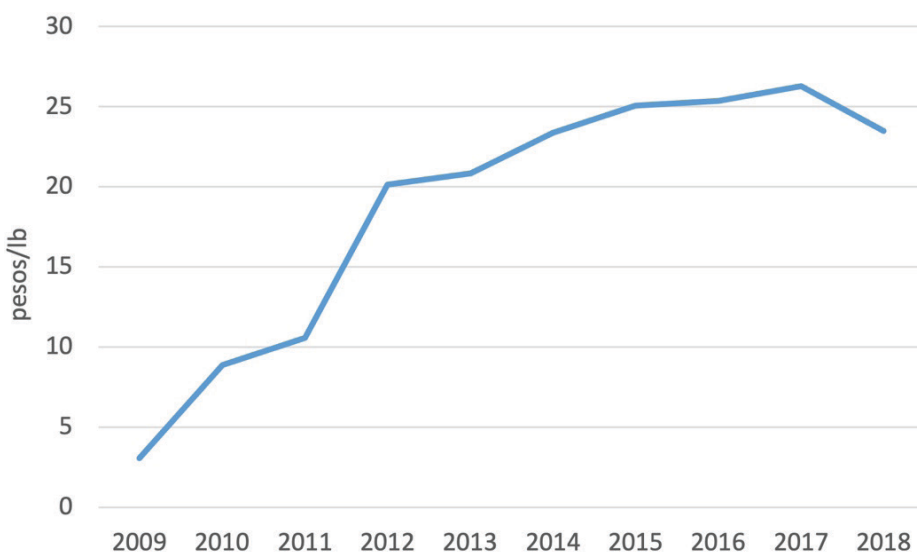

Figure 2. Prices Received by Mexican Growers, 2009-2018

Credits: SIAP, Mexico

\section{US-Mexico Blueberry Trade}

The vast majority of Mexican blueberries are exported to international markets. North America is the main export destination for Mexican blueberries, with the export markets in Europe and Asia lagging far behind (less than $3 \%$ of the total export). In North America, the United States is the largest importer of Mexican blueberries. According to the US Census Bureau (USCB 2020), the United States imported 76 million pounds of fresh blueberries in 2019, compared to 0.79 million pounds in 2009 (Figure 3). The months with high import volume are March, April, and May, accounting for $56 \%$ of total US imports of Mexican blueberries in 2019. These three months are also the major production window for Florida blueberries. In 2018, the United States imported 35 million pounds of Mexican blueberries from March through May. During the same period, Florida produced only 20.5 million pounds of blueberries (Figure 2). Because of Mexico's proximity to the United States, Mexican blueberries shipped via truck arrive fresh and are of good quality, making Mexico a major competitor for the Florida blueberry industry. The Mexican blueberry industry pays close attention to the diversification of its markets. It can ship blueberries to Europe within 22 days and to Asia within 15 days. Within a five-year period (2015-2019), the number of export destinations of Mexican blueberries almost doubled, increasing from 18 to 30 countries.

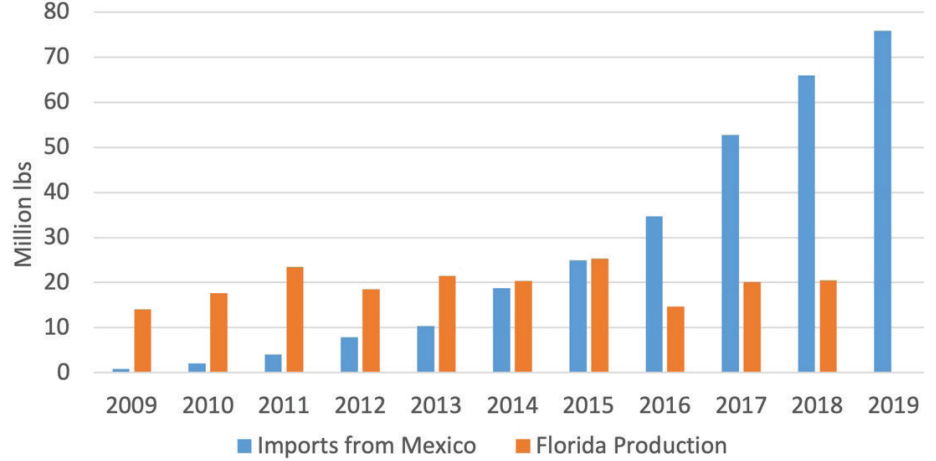

Figure 3. US Blueberry Imports from Mexico and Florida Production, 2009-2019

Credits: US Department of Commerce and US Department of Agriculture

\section{Cultural Practices}

Blueberries in Mexico are planted in single rows on soil mounded into raised beds using pine bark mulch to enrich the soil. In Mexico, bed-row spacing is 7.2 feet (2.2 meters) apart and in-row spacing is 2.1 feet ( 0.65 meter) apart, which are narrower than the plant row spacing of 9 by 2.5 feet in Florida (Singerman et al. 2016). As a result, common plant population is $2,830-3,240$ plants per acre $(7,000-8,000$ plants per hectare) in Mexico, compared to 1,936 plants per acre in Florida. Drip irrigation ensures constant water supply to the plants. Fertilizer application occurs every three days to provide the nutrient supply. In the first harvest, yield per plant is 1.43 pounds of fruit, which increases to 2.2 pounds of fruit starting in the second year. The cost summary reported by the Trusts Established with Relationship to Agriculture (FIRA) of Mexico shows the total cost to establish a blueberry open-field operation in Sinaloa in 2019 was 1,080,976 pesos per hectare, equivalent to US $\$ 21,058$ per acre. In comparison, Singerman et al. (2016) reported that Florida growers incurred a total establishment cost of US\$19,598 per acre in 2015. After establishment, blueberry growers significantly reduce their production expenditures associated with operation maintenance. The maintenance cost for those groves in year two or later was estimated at 448,585 peso per hectare (US $\$ 9,439$ per acre), which was comparable to the maintenance cost in Florida reported in 2015.

Mexican growers also produce blueberries in pots or containers (commonly plastic bags) under protected structures or in open fields. This practice occurs in areas where climate conditions are favorable but soils for cultivation are unsuitable. For pots/containers, substrates offer the ideal physical and chemical condition for blueberry plants. Therefore, a good mixture of substrates is a vital element in the success of a blueberry potting system. Advantages of this practice are highly effective and efficient water, weed, 
and nutritional management of blueberries. Although the productive potential per plant in pots is smaller than that in soil, the yield per acre is higher due to the denser plantation. For example, FIRA estimated an average yield of 10,706 pounds per acre in 2019 using the potting system versus 8,030 pounds per acre using the soil system $(4,740$ pounds per acre in Florida using the soil system). However, the yield advantage of the potting system comes with $95 \%$ higher establishment costs and $12 \%$ higher maintenance costs than establishment and maintenance costs incurred using the soil system.

\section{Factors Driving Growth}

Several factors are driving the growth of the Mexican blueberry industry. The first is government promotion through subsidies (Wu et al. 2018a; 2021), particularly the promotion of protected culture technology (Wu et al. 2018a). High tunnels and shade houses are the major protection structures used to produce high-quality blueberries in Mexico with an extended growing season. The subsidy rate in 2014 for high tunnels was 200,000 pesos (US\$14,451) per hectare and a maximum amount of 2.7 million pesos (US\$0.2 million) per project, and for shade houses, 300,000 pesos (US\$21,676) per hectare and up to 2.7 million pesos (US $\$ 0.2$ million) per project. Due to these favorable policies, there was a major shift from open-field production to protected-culture production. According to the Mexican Ministry of Agriculture, open-field and protected-culture blueberry acreages were 6,289 and 198 acres, respectively, in 2015, compared to 3,289 and 4,635 acres, respectively, in 2016 (Figure 4).

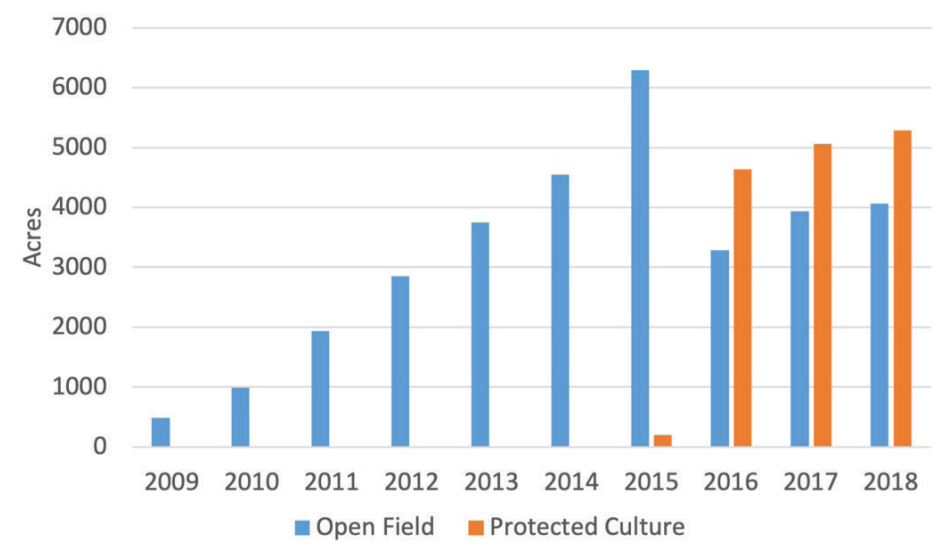

Figure 4. Mexican Blueberry Acreage under Different Production Technologies, 2009 to 2018.

Credits: SIAP, Mexico

The second factor is the higher profitability of this crop, attracting growers to switch from other crops to blueberries. Mexico produces and ships blueberries in the months of higher blueberry prices, which makes it more profitable. The cost summary reported by the Trusts Established in
Relation to Agriculture in Mexico shows that the profit of blueberry production under protected structures in the Michoacán region was 1.5 times that of strawberry production in the 2019/2020 season (FIRA 2020). Agricultural production in Mexico has low labor costs compared to Florida. In 2019, the average wage of farmworkers in Mexico was 225.57 pesos per day (for a 10-hour workday), equivalent to US $\$ 1.2$ per hour. In comparison, the minimum wage rate (adverse effect wage rate, AEWR) required for hiring $\mathrm{H}-2 \mathrm{~A}$ guest workers in Florida was US\$11.24 per hour in 2019, and the average wage was even higher. The cost summary reported by FIRA in Mexico shows growers incurred 106,750 pesos for harvesting 12 tonnes of blueberries, equivalent to US $\$ 0.21$ per pound harvested, while Florida growers incurred US $\$ 1.96$ per pound of harvesting and marketing costs (Singerman et al. 2016). As for the total production cost, it cost $\$ 1.6$ to produce one pound of Mexican blueberries, but almost $\$ 3$ for one pound of Florida blueberries in 2019. The competitive advantage of Mexican blueberries in production/labor costs is prominent, even after accounting for the transportation cost (the transportation cost was only 3 cents per pound higher from Mexico through Nogales, Arizona, to Chicago, compared with the cost from Florida to Chicago). The profitability of this crop has attracted investment from both Mexican and foreign companies.

Other factors driving the growth of the Mexican blueberry industry include large demand in the US market and free access to the market under NAFTA/USMCA. Mexico has also been expanding and diversifying its market to cover areas with large blueberry demand, such as China. The blueberry industry in Mexico will continue to grow in coming years.

\section{Concluding Remarks}

This publication provides an overview of the Mexican blueberry industry, which has seen rapid growth in the past decade. Higher profitability and favorable policy have attracted investment capital and accelerated grower adoptions of the crop in Mexico. Mexico's blueberry production will continue to expand given its competitive protected culture technologies. Because of the overlapping production window and rapidly increasing imports of Mexican blueberries, Florida growers are no longer enjoying high prices in the early season as in the past. The average price farmers received was $\$ 4.90$ per pound between 2002-2010 but only $\$ 3.51$ per pound between 2011-2019. It dropped from $\$ 6.3$ per pound in 2005 to $\$ 2.6$ per pound in 2019 . The US government initiated a Section 201 safeguard investigation in 2020 but it did not lead to trade remedies as 
petitioned by the US domestic industry. The investigation is part of a larger dispute in fresh produce trade between the United States and Mexico that has impacted major fruit and vegetable crops, including strawberries (Suh et al. 2017), tomatoes (Guan et al. 2018; Wu et al. 2018b; Li et al. 2021), peppers (Biswas et al. 2018), and cucumbers and squash. U.S.-Mexico competition in blueberries and other fresh produce is expected to further intensify in coming years.

\section{References}

Biswas, T., Z. Guan, and F. Wu. 2018. "An Overview of the US Bell Pepper Industry.” FE1028. EDIS 2018 (2) https:// doi.org/10.32473/edis-fe1028-2017.

FIRA, Los Fideicomisos Instituidos en Relación con la Agricultura, Mexico. Sistema de costosagrícolasResumen de costos. Available at: https://www.fira.gob.mx/InfEspDtoXML/TemasUsuario.jsp

Guan, Z., T. Biswas and F. Wu. 2018. “The US Tomato Industry: An Overview of Production and Trade." FE1027. EDIS 2018 (2). https://doi.org/10.32473/edis-fe1027-2017..

Li, S., F. Wu, Z. Guan, and T. Luo. 2021. How Trade Affects the US Produce Industry: The Case of Fresh Tomatoes.

International Food and Agribusiness Management Review, in press. https://doi.org/10.22434/IFAMR2021.0005.

Rabobank, 2019. Newcomers Reshaping the US Fresh Blueberry Market: What to Expect in 2019/20 and Beyond. Rabobank.com.

Singerman, A., M. Burani-Arouca, J. G. Williamson, and G. K. England. 2016. Establishment and Production Costs for Southern Highbush Blueberry Orchards in Florida: Enterprise Budget and Profitability Analysis. FE1002. Gainesville, FL: UF/IFAS Extension. http://edis.ifas.ufl.edu/fe1002.

Suh, D. H., Z. Guan, and H. Khachatryan. 2017. “The Impact of Mexican Competition on the US Strawberry Industry." International Food and Agribusiness Management Review 20:591-604. https://doi.org/10.22434/

IFAMR2016.0075.

United States Census Bureau (USCB). 2020. World Trade Atlas. Washington, DC: U.S. Census Bureau.

Wu, F., A. Caro-Soto, and Z. Guan. 2021. “Government Support in Mexican agriculture: The Agri-Food Productivity and Competitiveness Program." FE1107. EDIS 2021 (6) https://edis.ifas.ufl.edu/publication/FE1107.
Wu, F., B. Qushim, M. Calle, and Z. Guan. 2018a. "Government Support in Mexican Agriculture." Choices 33 (3): 1-11. https://www.jstor.org/stable/26583607.

Wu, F., Z. Guan and D. H. Suh. 2018b. “The Effects of Tomato Suspension Agreements on Market Price Dynamics and Farm Revenue." Applied Economic Perspectives and Policy 40 (2): 316-332. https://doi.org/10.1093/aepp/ ppx029. 